\title{
APORTES A LA PROBLEMÁTICA CIENCIA-ESPIRITUALIDAD DESDE EL BUDISMO ZEN
}

\author{
José Arlés Gómez Arévalo
}

\begin{abstract}
En varios campos de la ciencia actual se pueden encontrar investigadores que creen que las teorías científicas muestran más afinidad con las cosmologías y tradiciones hindúes y budistas que con las epistemologías de corte meramente occidental. El influjo de las ideas orientales es mucho más extenso que la simple difusión de ideas religiosas o pseudorreligiosas. Se puede detectar la perspectiva oriental del mundo conformando ideas en filosofía, teoría política, psicología, educación y medicina.
\end{abstract}

John White

\section{Resumen}

Como fruto de la reflexión entorno al tema de "ciencia y espiritualidad", se ha venido indagando, en este trabajo investigativo, por las conexiones que se pueden establecer entre el mundo de la ciencia occidental y la espiritualidad oriental. Este trabajo ha sido elaborado desde los presupuestos de la física cuántica y la teoría de la complejidad, en contraste con las antiguas tradiciones espirituales del lejano Oriente, concretamente, por el aporte del budismo zen, ya que desde sus fundamentos teórico-prácticos proporciona elementos básicos en la comprensión de las problemáticas del hombre contemporáneo a nivel del conocimiento, el arte, la ciencia y la espiritualidad.

Las eternas preguntas, que han sido explicadas por las antiguas tradiciones espirituales y otras veces por las filosofías convencionales, hoy por hoy conducidas por la mano de científicos altamente reconocidos por la comunidad científica occidental, arrojan resultados tales que pareciera ser que la brecha entre ciencia y espiritualidad, que comenzó desde tiempos remotos, se está cuestionando a la luz de las nuevas teorías de la física cuántica, la teoría sistémica,

Docente Departamento de Humanidades, Universidad Santo Tomás, Teólogo y Magíster en Filosofía, Director del Proyecto “Ciencia-Espiritualidad" y del grupo de investigación inscrito en Colciencias (2005). Correo electrónico: intiyang@hotmail.com. 
la psiconeuroinmunología, la neuroteología y muchas otras derivadas de las reflexiones, los experimentos y las tecnologías que se han implementado en los últimos tiempos y que pretenden dar respuesta a los problemas ya planteados.

\title{
Palabras clave
}

Zen, meditación, conciencia, ilusión, luz, energía, onda, prácticas mente-cuerpo, espiritualidad, cosmos, ciencia

\begin{abstract}
As a result of the thoughts around the topic "Science and Spirituality" it has been investigated, in this research, by the links that can be established among the western science world and the eastern spirituality. This work, has been elaborated from the assumptions of the quantum physics and the theory of complexity in contrast with the ancient spiritual traditions of the far East, concretely, in particular by the contribution of the Buddhism-Zen, since its theoreticalpractical foundations, provide basic elements for understanding the problems of the contemporary human being in the levels of knowledge, art, science and the spirituality.

The eternal questions which have been explained by the ancient spiritual traditions and sometimes by the conventional philosophies, at this precise moment, lead by the hand of well known scientists within the western scientific community, produces results which seems that the division between science and spirituality, that began far off times, is questioned based on the new theories of the quantum physics, the systematic theory, the psycho-neuro-immunology, the neurotheology, and many others derived from the thoughts, the experiments and the technologies that have been implemented in recent years and that hope to give answer to the problems already set out.
\end{abstract}

\section{Key words}

Zen, Conscience, hope, light, energy, wave, mind-body, practice, spirituality, cosmos, science.

\section{Introducción}

Preguntas como: ¿Por qué estamos aquí? ¿De qué están hechos los pensamientos? ¿Vemos el mundo tal como es? ¿Qué es la energía? ¿Qué es el espíritu? ¿Qué es la realidad? ¿Cómo podemos crear conscientemente nuestros actos? ¿Cuál es el poder de la intención? ¿Cómo experimentamos nuestras conexiones cerebrales? ¿Cómo podemos superar las experiencias del pasado?, son algunas de las que los seres humanos nos hemos formulado desde épocas remotas. Hoy por hoy, en esta nueva perspectiva de estudio entre la ciencia occidental y la espiritualidad oriental, dichas preguntas recobran su sentido desde la perspectiva del estudio mente-cere- bro, espíritu-energía-conciencia, ser humano-naturaleza. Este trabajo investigativo aborda estas problemáticas desde el encuentro entre algunas de llamadas "ciencias emergentes" y las tradiciones espirituales del lejano oriente, concretamente, en este caso se asumirá la reflexión desde el aporte del budismo zen.

Hasta hace casi un siglo, la ciencia moderna pisaba un terreno donde todo le era muy claro. A través de la química, la biología y la física un científico podía evaluar prácticamente cualquier suceso y describirlo sin rango de error, pero este estudio se limitaba siempre al mundo material. La religión entonces tomaba lo que quedaba: espiritualidad, sentido de la vida, superviven- 
cia del alma a la muerte, etc. Hoy la misma ciencia, a partir del aporte de las neurociencias, la física cuántica y la teoría de la complejidad, reconoce que está sometida al campo de las probabilidades y que no puede desconocer el aporte que le hacen las tradiciones espirituales milenarias en la búsqueda de nuevas respuestas a las problemáticas entorno al conocimiento, el origen del hombre y el universo, la naturaleza del cerebro, la mente y el espíritu. Un ejemplo de ello se dio en 1900, cuando el físico Max Planck, tratando de resolver un problema de radiación, expuso una teoría que decía que la energía, al igual que la materia, está formada por pequeñas unidades llamadas «cuantos», en vez de ser un continuo energético como se había pensado con anterioridad. El estudio de la física cuántica cambia todo nuestro entendimiento sobre los fundamentos básicos del universo conocido. Con ella, la ciencia física ingresó sin proponérselo a este campo que tradicionalmente había sido terreno religioso, Ilamado «mundo o plano espiritual». Esto nos ha llevado a muchas conclusiones científicas, morales y espirituales. En otras palabras, la física cuántica ha demostrado que somos cocreadores del universo, junto con las ideas que de la trascendencia poseen los grandes sistemas de pensamiento religioso y espiritual tanto en Occidente como en Oriente. En el caso de las grandes tradiciones de pensamiento oriental, el budismo zen va a jugar un papel crucial en la actual comprensión entre cienciaespiritualidad, desde la conexión mente-cerebro-energía-espíritu, hombre-naturaleza. Desde esta perspectiva se asume el aporte del presente trabajo investigativo.

Hoy, como diría el maestro zen Taishen Deshimaru ( EI anillo de la vía, Kairós, 2002), cuando recordamos ese antiguo Koan zen que nos pregunta «Si un árbol cae en el bosque y no hay nadie presente, ¿éste hace ruido?»; desde el punto de vista de la ciencia física newtoniana la respuesta era «sí, hace ruido, por que el sonido son ondas que se generan como resultado del choque de la materia con la materia», pero desde el punto de vista cuántico la respuesta es otra: el árbol no hace ruido a menos que una conciencia lo configure de esta manera, en ausencia de una conciencia humana las partículas que componen el árbol, así como las partículas con las que choca, simplemente reaccionan de maneras impredecibles y no generan sonidos porque las partículas subatómicas no son ni partículas ni ondas. Son ambas cosas al mismo tiempo.

A la luz de estos descubrimientos, muchas cosas que tradicionalmente han sido clasificadas como exclusivamente espirituales toman un sentido científico: la plegaria, la afirmación metafísica, la oración científica, la meditación y la visualización creativa son funciones elevadas de la conciencia humana, y estas funciones interactúan con la realidad de manera específica en el mundo cuántico, que es la matriz del mundo material, ya que es aquí donde la energía se convierte en materia. El segundo aspecto que podemos conectar con lo espiritual es la descripción de estas partículas subatómicas, que son los elementos de los que está formada la realidad material. Estos elementos están formados en un $99 \%$ de vacío y solamente en un $1 \%$ de algo que ni siquiera es sólido, pero al menos tiene propiedades medibles. Entonces la realidad material cambia radicalmente. Ya no se puede afirmar que la realidad que percibimos en el plano físico es veraz, puesto que está conformada, según la teoría cuántica, por elementos que nada contienen. Desde los planteamientos de una de las más grandes tradiciones del lejano oriente, el budismo zen, se pueden rastrear importantes aportes a la problemática "ciencia-espiritualidad".

\section{El budismo zen y la búsqueda de la iluminación}

\begin{abstract}
Antes de estudiar zen, las montañas son montañas y los ríos son ríos; mientras estás estudiando zen, las montañas ya no son montañas y los ríos ya no son ríos; pero una vez que alcanzas la iluminación las montañas son nuevamente montañas y los ríos nuevamente ríos.
\end{abstract}

Aforismo Zen

Cuando la cultura china entró en contacto con el pensamiento hindú, en la forma del budismo, alrededor del siglo I d.C., dos desarrollos paralelos sucedieron. Por un 
lado, la traducción de los sutras budistas estimularon a los pensadores chinos y los llevó a interpretar las enseñanzas del Buda hindú a la luz de sus propias filosofías. De esta manera surgió un muy fructífero intercambio de ideas, que culminaron en la escuela Hua-yen sanscrito: Avatamsaka- de budismo en China y la escuela Kegon de Japón.

Por otro lado, lo pragmático de la mentalidad china respondió al impacto del budismo hindú, concentrándose en los aspectos prácticos y desarrollándolos en una forma especial de disciplina espiritual que recibió el nombre de cha'an, una palabra normalmente traducida como "meditación". Esta filosofía cha'anfue eventualmente adoptada por Japón, alrededor del año 1200, y ha sido cultivada allí bajo el nombre de zen, una tradición que se mantiene viva hasta la actualidad.

Zen es una mezcla única de filosofías e idiosincrasias de tres culturas diferentes. Es una forma de vida típicamente japonesa, y aún así refleja el misticismo de la India, el amor de la naturalidad y espontaneidad del taoísmo y el pragmatismo profundo de la mente confucianista.

A pesar de su carácter polifacético, el zen es puramente budista en su esencia, pues su objetivo no es ni más ni menos que el de Buda: lograr la iluminación, una experiencia conocida en zen con el nombre de "satori". El maestro Deshimaru dice sobre el satori: "El satori es como el reflejo de la luna en el agua; la luna no se moja y el agua no se enturbia. La luz de la luna aclara hasta el infinito; aclara toda la tierra, pero también puede estar contenida en una minúscula gota de agua"2.

La experiencia de la iluminación, satori, es la esencia de todas las escuelas de filosofía orientales, pero el zen es la única que se concentra exclusivamente en esta experiencia y no está interesada en ninguna interpretación más allá de ésta. En palabras de Suzuki, el maestro zen más conocido en Occidente: "Zen es la disciplina de la iluminación"(Zenko Suzuki, El zen, El Vecchi, 1999). Desde el punto de vista del zen, el despertar de Buda y sus enseñanzas eran que todos tenemos el potencial para lograr la iluminación. Tal es la esencia del Budismo. El resto de la doctrina, incluido en los voluminosos sutras, es visto solamente como suplementario.

La experiencia del zen es, por lo tanto, la experiencia de la iluminación, de satori, y ya que esta experiencia, finalmente, trasciende toda categoría de pensamiento, no se interesa en ninguna abstracción ni conceptualización. No tiene ninguna doctrina o filosofía especial, ningún credo ni dogma formal y enfatiza su libertad de todo pensamiento fijo, esto la hace verdaderamente espiritual.

El zen puede ser pasado de maestro a discípulo, y ha sido, de hecho, transmitido por muchos siglos por métodos especiales propios del zen. Un primer paso, que ejemplifica la tarea del maestro, es la frase que le dice cuando inicia su proceso: "Compórtate de forma natural y ligera; permite que todo siga su ritmo; libérate de todo apego. Esto basta para asegurar el despertar completo" $^{\prime \prime}$.

Los maestros zen no son adeptos a la especulación. De esta manera, prefieren desarrollar métodos que apuntan directamente a la contemplación de la "realidad", con acciones y palabras repentinas y espontáneas, que exponen paradojas del pensamiento conceptual llamados "koans". Los koans están orientados a parar el proceso mental del pensamiento, preparando así al estudiante a la experiencia mística, de mayor aprecio que la mera aprehensión racional.

En zen, satori significa la inmediata experiencia de la auténtica naturaleza de todas las cosas. Lo primero y más importante son los objetos, hechos y personas involucrados en la vida cotidiana, de tal manera que aunque enfatiza las cosas prácticas de la vida, zen es profundamente místico como experiencia. Al vivir en-

Deshimaru, El anillo de la vía. Op. Cit., p. 65.

3 Autores Varios. Tradición zen, Buenos Aires: Troquel, 2000, p. 46. 
teramente en el presente, dándole atención completa a los asuntos diarios, alguien que ha logrado satori experimenta la admiración y misterio de la vida en cada situación: Desde la manera como se camina hasta la forma como se respira.

El énfasis sobre la naturalidad y espontaneidad muestra claramente las raíces taoístas, pero la base para este énfasis es estrictamente budista. Es la creencia en la perfección de la naturaleza original, la realización de que el proceso de iluminación consiste meramente en transformarnos en lo que ya somos desde un principio. Cuando se le preguntó al maestro zen Po-chang sobre buscar la naturaleza de Buda, respondió: "Es muy parecido a montar un buey en búsqueda de un buey".

Actualmente hay dos escuelas principales de zen en Japón, que difieren en sus métodos de enseñanza. La escuela rinzai o "repentina" utiliza el método koan, se da prominencia a entrevistas formales periódicas. Las escuelas zen, especialmente la soto y la rinzai, que son las más extendidas, apuntan hacia la maduración gradual del estudiante zen, "como la brisa de primavera que acaricia la flor, ayudándola a florecer" ${ }^{\prime \prime}$. En ambas escuelas "el sentarse tranquilo" es la mejor forma de meditación, por ello se le confieren la mayor importancia a "zazen", o meditación sentada, que es practicada en los monasterios zen todos los días durantes muchas horas. La postura correcta y la respiración son las primeras cosas que debe aprender un estudiante de zen. En el zen rinzai, zazen es usado para preparar la mente intuitiva y así manejar el koan, la escuela zen soto lo considera la forma más importante para ayudar al estudiante a madurar y evolucionar hacia satori: cuerpo $y$ mente se fusionan en una unidad armónica que no requiere ninguna "mejoría" desde la mentalidad occidental. Como dice un poema zen: "Sentado tranquilo, ha- ciendo nada, la primavera llega, y el pasto crece por sí sold ${ }^{\prime 6}$.

La espontaneidad, simplicidad y total presencia de la mente, característica del zen, las actividades lentas y rituales de cha-no-yu, la ceremonia japonesa del té, los movimientos de manos espontáneos requeridos para la caligrafía, la pintura y la espiritualidad de bushido, "la vía del guerrero", son manifestaciones de la fusión entre mente-espíritu o cuerpo-energía. Mientras que las actividades anteriores requieren de la perfección de la técnica, la maestría real sólo se logra cuando se trasciende la técnica y el arte se transforma en un "arte sin arte", brotando del subconsciente, no de la intención de fabricar objetos que impresionen los sentidos ${ }^{7}$.

\section{El "Ku soku ze shiki" y el sentido del vacío en el budismo zen}

\author{
El vacío se vuelve fenómeno, \\ los fenómenos se vuelven vacio. \\ Taishen Deshimaru
}

En la tradición del budismo zen, el término ku designa el vacío, la vacuidad, la naturaleza misma de todo el mundo manifestado. Shikidesigna los fenómenos, la realidad fenomenal, todo aquello que podemos percibir, ver, oler, medir, sentir. La frase del maestro Deshimaru es fundamental en el budismo zen. Viene a decir que la vacuidad - $k u$ - se convierte continuamente en fenómeno -shiki y que los fenómenos se convierten continuamente en vacuidad; esto es similar a los experimentos que han realizado algunos físicos cuánticos: De la vacuidad surge un movimiento, una energía que se manifiesta también en el mundo humano, una energía que llena el cosmos entero. Es la ener-

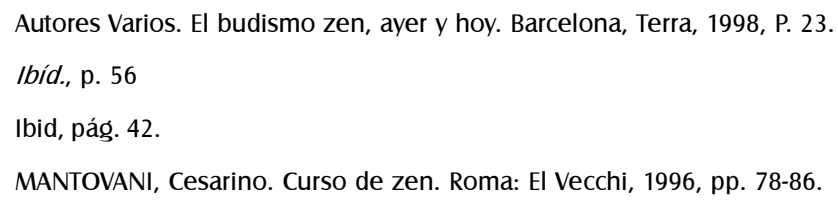


gía cósmica, la vitalidad cósmica. La vida, según esta tradición, es fruto de esta energía cósmica. El sutra de la Gran Sabiduría lo expresa así: "Shiki fu i ku: Ios fenómenos no son diferentes del Vacío. Ku fu i shiki: el vacío no es diferente de los fenómenos. Shiki soku ze ku: Ios fenómenos son vacío. Ku soku ze shiki: el vacio es fenómeno"s.

La iluminación o liberación en el budismo, como se explicará posteriormente, sucede cuando cesa el reflejo, normalmente automático, de la conciencia, lo que es experimentado como un dejar ir y caer en el vacío. «El ser humano teme olvidar su mente, temiendo caer al vacío sin nada que frene su caída. No sabe que el vacío en realidad no es vacío, sino la esfera del verdadero Dharma» (Huang-po, Sabiduría zen y sentido del vacío, Nueva Cork: Plenun, 1987). Lo que tememos como la nada en realidad no es la nada, ya que es la perspectiva de un sentido del yo sin fundamento, atrapado por el miedo de perder la sujeción de sí mismo. Cuando se pierde el miedo a la "nada", al "vacío", cuando se tiene el coraje de dejarse caer en ella fundiéndose en ella, esa nada conduce a otra cosa, el origen común de lo que experimento como nada y de lo que experimentamos como "el yo". En palabras de Peter Kelder, investigador asiduo del budismo tibetano:. "Cuando la conciencia para de intentar atrapar su propia cola, me convierto en nada, y descubro que soy todo - o, más precisamente, que puedo ser cualquier cosa»"

En términos no dualistas del budismo mahayana, la escuela budista más extendida en Oriente, es necesario tomar conciencia de que la mente es una con todo el universo. Esto es posible si el núcleo de la propia conciencia del ego no es auto-existente sino vacío, puesto que no tiene fundamento: si la conciencia no está «den- tro», no hay "fuera», pues es la energía total. En la vida humana esta energía se articula principalmente en cuatro niveles: corporal, emocional, mental y espiritual. En el nivel corporal, la energía vital se vuelve tan densa que se materializa, se cosifica, se solidifica. En la configuración de la vida, la energía cósmica va articulándose desde los niveles de organización más simples a los evolutivamente más complejos. Esto es, desde el primigenio óvulo fecundado hasta el estado de un ser plenamente despierto. En este proceso evolutivo encontramos que la energía contenida en el óvulo fecundado va tomando, en primer lugar, la forma de cuerpo humano. En el próximo nivel de organización aparece la vida emocional. A continuación la vida mental y, por último, la vida espiritual, o la aparición de una conciencia superior de ser. En el nivel espiritual, según la concepción del budismo zen, el nivel de la conciencia se expande.

En el canon Pali, las dos descripciones más famosas del nirvana se refieren a "lo no-nacido", donde "no se encuentran ni este mundo ni el otro, ni venir, ni ir ni quedarse, ni muerte ni nacimiento, ni objetos sensoriales ${ }^{10}$. Afirmaciones similares son comunes en el Mahayana. El término más importante en esta tradición es sunyata, "vacío»; los adjetivos usados con más frecuencia para explicar sunyata son: «no-nacido», «no-creado» y «noproducido.» El «Sutra del Corazón» explica que todas las cosas son sunyata porque "no hay ni nacimiento ni muerte, ni pureza ni impureza, ni crecimiento ni disminución " "1 . Según los estudiosos de la tradición budista, el universo entero procede de la luz: "La luz, esa forma de energía primordial tan misteriosa, es la fuente de toda creación en el budismo. Es el sustrato que subyace y del que están hechas todas las cosas. Y esto no en sentido figurado, sino real, dicha luz es eterna, no ha tenido principio ni tendrá fin"12.

\footnotetext{
Desmedí, Evely y Dussausoy, Dominique. Los sutras budistas, Buenos Aires: Troquel, 1998, p. 78.

Kelder, Meter. El budismo tibetano. Barcelona: Plaza y Janés, 1999, p. 57.

Lawden, Friedich. El canon Pali y la tradición budista. Sao Paulo: Curitiba, (Brasil): 1982.

Ibíd., p. 89.

Ibíd., p. 97.
} 
Otra palabra clave para entender la problemática ciencia-espiritualidad desde el budismo zen, está relacionada con la pulsación. La pulsación, esta polaridad, descubierta por la física cuántica, era algo conocido por las experiencias espirituales antes que por la vía científica. Las antiguas tradiciones espirituales de Oriente, especialmente el taoísmo, y también el budismo, ya mencionaban en sus textos este fenómeno físico-químico. En el taoísmo se llama ying-yang, la pulsación fundamental; en el budismo es la base misma de la sabiduría descubierta y enseñada por Buda. En el sutra de la Gran Sabiduría Maka Hannya Haramita Shingyo, encontramos la siguiente frase: "La vida humana se percibe como una vida muy especializada, con una estructuración muy especializada de la energía cósmica. Dicha energía pulsa y vibra en el cosmos. Formamos parte de un todo"13. En el universo budista, favorecer la evolución es favorecer la pulsación de la energía en cualquiera de sus niveles de organización. Desde el punto de vista del budismo zen, la energía cósmica pulsa o gira continuamente en la llamada Rueda de la vida y de la muerte o Rueda del samsara: desde la Luz primigenia, o principio y fin de todo proceso energético (máximo nivel de sutileza), a la concepción (máximo nivel de densidad); $y$ desde la concepción hasta la posibilidad de reabsorción en la Luz que sobrevive a la muerte (Howard Sochurek, La senda del budismo, Nueva York: Golden Press, 1987).

\section{La meditación y la experiencia del dhyana}

\author{
El cielo ilimitado, \\ las miríadas de estrellas, \\ el astro lunar y el astro solar, \\ las innumerables nebulosas \\ y nuestra tierra \\ han sido creados por la luz, \\ fuente de la vida.
}

Taisen Deshimaru
La tradición espiritual zen, mediante la meditación, ha utilizado técnicas psico-físicas que permiten experimentar una realidad extra-temporal, es decir, eterna e infinita, esta afirmación ha sido corroborada por investigadores occidentales, entre ellos Danah Zohar (Inteligencia Espiritual, Ediciones Plaza y Janés, Barcelona, 2004) y Joao Da Silva (Budismo, Ediciones Pensamiento, Sao Paulo, 1998).

Schrödinger, llegaría a decir: "La representación que del mundo posee cada ser humano es y siempre será una construcción de su mente; $y$ no puede demostrarse que posea una existencia aparte" ${ }^{\prime 14}$. La meditación budista es un aprendizaje "mental". Se enseña a usar la atención, a usar y a tomar conciencia de la luz de la conciencia misma. A lo largo de este aprendizaje, el meditante aprende primero a enfocar su atención y a iluminar con ella los múltiples campos y niveles de su experiencia en tanto que existencia en el espacio-tiempo. Por ejemplo, el meditante aprende a identificar cada una de las sensaciones provenientes de los cinco campos sensoriales (visual, auditivo, táctil, gustativo, olfativo). Aprende a ser continuamente consciente de su respiración, de sus emociones, de sus pensamientos, del funcionamiento de su mente categórica. Aprende a iluminar su inconsciente (patrones de conducta, emocionales y cognitivos que usualmente operan por debajo del umbral de la conciencia). En resumen, el meditante toma claramente conciencia del aspecto condicionado de su existencia. Se podría decir que esta es la primera parte del entrenamiento o del aprendizaje de la meditación: darse cuenta del estado de la propia mente. Otro aspecto muy importante de este aprendizaje consiste en una desidentificación progresiva de los distintos niveles del ser condicionado. En el camino de la meditación budista se habla de diversos niveles: Ios cuatro primeros son llamados en sánscrito dhyana, que literalmente significa "absorción".

En el primer nivel de dhyana, el meditante observa las sensaciones que experimenta y se desidentifica de ellas.

$13 \quad$ Ibíd., p. 67.

14 Dodds, John. Comentarios a la obra de Schrödinger: la teoría física. En Journal of The Society for Psychical Research, No. 57, p. 288. 
La expresión de este estado de conciencia podría ser expresada así: "Estas sensaciones forman parte de mí, pero yo no soy estas sensaciones". El sentido de identidad se retira de las sensaciones.

En el segundo nivel de dhyana, el meditante observa las emociones que experimenta y se desidentifica de ellas. "Estas emociones forman parte de mí, pero yo no soy estas emociones". El sentido de identidad se retira de las emociones.

En el tercer nivel de dhyana, el meditante observa los contenidos de su mente: pensamientos, relaciones lógicas, fantasías, ideación, etc., y se desidentifica de todo ello. "Estos contenidos mentales forman parte de mí, pero yo no soy estos contenidos mentales". El sentido de identidad se retira de los contenidos mentales.

En el cuarto nivel de dhyana, el meditante observa sus patrones inconscientes y en general todos aquellos contenidos que usualmente permanecen por debajo del umbral de la conciencia. "Estos contenidos del inconsciente forman parte de mí, pero yo no soy estos contenidos". El sentido de identidad se retira de los contenidos inconscientes. Este cuarto nivel de dhyana da paso a otros estados muy sutiles de conciencia, agrupados en el llamado por el budismo "mundo de la no-forma", debido a que en estos estados, la conciencia que tenemos de las formas: Materia, formas sensoriales, formas emocionales, formas intelectuales, formas psíquicas, etc., comienza a desaparecer o disolverse.

Según el maestro zen Dokushô Villalba ${ }^{15}$, antes de la aparición de la ciencia, de la de la teoría de la relatividad y de la mecánica cuántica, han existido seres humanos que no sólo descubrieron que la naturaleza y el origen de todas las formas de vida es la luz, sino que lo expe- rimentaron, es decir, ellos mismos se convirtieron en luz, o como se dice en el lenguaje popular, en "iluminados". Según Villalba, si se consigue desacelerar una gran cantidad de energía, ésta se solidifica en materia, esto se logra mediante la práctica de la meditación, que "es un proceso a través del cual la materia se transforma en energía, y la energía en luz, en la luz de la conciencia. Zen es la reabsorción de la materia en su fuente y sustancia original: la luz. Y como hemos visto, en la luz no hay tiempo ni espacio ni materia, ni ida ni venida" $^{\prime \prime 6}$.

Mediante la meditación zen, neurobiólogos y neuropsiquiatras han podido corroborar que se suceden los siguientes procesos en las personas que la practican:

- Disolución de la fijación en los objetos del deseo y de los objetos sensoriales

- Disolución de la fijación en la emocionalidad polarizada

- Disolución de la fijación en los contenidos mentales

- Purificación de las tendencias distorsionadas del inconsciente

- Disolución de la fijación en el yo temporal

- Disolución de la fijación en el yo espacial

- Disolución de la fijación en la conciencia individual

- Realización de la vacuidad

- Emergencia de la Luz clara, no-nacida, no-extinta 


\section{La conciencia y la experiencia del satori}

\author{
Oh Conciencia!, motor de la vida, eres más \\ rápida que la luz.
}

Trasciendes el tiempo y el espacio. La libertad es tu naturaleza.

La eternidad es tu duración. Eres como el sueño: con él te fundes en el mismo mundo: el de la libertad y la eternidad.

Taisen Deshimaru

En el budismo se dice que la naturaleza esencial de nuestra vida es la conciencia. La vida es conciencia, surge de la conciencia y desemboca en la conciencia (Italo Sordi, Budismo. Roma: Futuro, 1981). El término "conciencia" debe ser entendido aquí tanto como origen de la energía como la forma más elevada de energía, su último nivel de organización. En el budismo esta conciencia recibe también el nombre de "Luz primigenia". Según la tradición budista, la naturaleza del hombre es ser Luz. Esto es lo que realmente somos. Esta "Luz" que somos aquí y ahora no es estática. Más bien es pulsátil. Esta pulsación oscila entre dos polos: máxima densificación (movimiento hacia la materialización, energía trasformándose en materia) y máxima sutileza (materia transformándose en energía). Siguiendo las investigaciones de Nikhilanahda, podríamos decir, desde la visión del budismo zen, que " La conciencia es la capacidad que tiene la energía de ser ella misma, de verse a ella misma, de ser consciente de ella misma, en definitiva de ser, es decir, de alcanzar su máxima identi$\mathrm{dad}^{\prime \prime} 17$.

Desde el punto de vista del budismo todas las realidades surgen de la misma fuente: La facultad universal de la conciencia. La conciencia es una y universal y no se limita a los seres humanos. Lo penetra todo. Ahora bien, dado que los seres vivientes somos muy diferentes unos de otros (diversidad de sujetos conocedores), los procesos cognitivos a través de los cuales se manifiesta la facultad de la conciencia son muy diferentes también los unos de los otros, dando lugar a conocimientos diferentes de la realidad, o lo que es lo mismo, a realidades diferentes.

Los animales están dotados de la facultad de la conciencia. Su conocimiento de la realidad viene dado por su propio proceso cognitivo, el cual está condicionado por sus características individuales. Lo mismo sucede con las plantas e incluso con los seres mal llamados inertes, o inorgánicos. Todos tienen un cierto conocimiento de la realidad, por lo tanto participan de alguna manera de la luz de la conciencia. El budismo distingue cuatro estados de conciencia en el mundo de la no-forma. Estos estados son llamados genéricamente samapatti, en sáncrito, literalmente significa: arrobamiento, rapto, embeleso.

El primer samapatti es llamado "espacio infinito". Hoy habría que llamarle "espacio-tiempo infinito". En este estado, el meditante disuelve la conciencia espacial. Disuelve "la percepción de ser un cuerpo sólido ocupando un espacio concreto en el espacio universal"; también, disuelve "la percepción de ser un ente definido ocupando un punto concreto del tiempo". El meditante se convierte en espacio-tiempo infinito. La conciencia de su individualidad se disuelve y se funde en una conciencia de infinitud, tanto espacial como temporal. El segundo samapatti es llamado "conciencia infinita". El tercer samapatti es llamado "vacuidad de la conciencia". El cuarto samapatti es llamado "ni percepción ni no-percepción", es decir, la total experiencia del vacío $^{18}$.

La luz de la conciencia es lo que nos permite, según el Zen, conocer cualquier objeto del conocimiento. Des-

7 Mandukya Nikilanahda. El budismo. New Cork: Centro Vivekananda, 1990, p. 78.

$18 \quad$ Villalba. Op.Cit., p.57. 
de el punto de vista del Budismo, es imposible aprehender conceptualmente lo que es la conciencia en sí. Ahora bien, como de alguna manera tenemos que referirnos a ella, se le asignan tres características: Es idéntica a la naturaleza de la luz, incluye y trasciende la totalidad del espacio-tiempo y es vacua.

A continuación se explicará cada una de estas características:

$1 \quad$ Es idéntica a la naturaleza de la luz quiere decir que es gracias a ella y solo gracias a ella que las cosas son lo que son y nosotros podemos conocerlas, de la misma manera que es gracias a la luz física como podemos ver la forma y el color de los objetos y la forma y el color de nuestro propio cuerpo. La conciencia, como la luz, es invisible en sí, pero gracias a ellas podemos ver o conocer. Aquello de lo que aún no se ha tomado conciencia, no puede ser conocido. La conciencia es la presencia invisible gracias a la cual la realidad puede ser percibida en sus múltiples aspectos y niveles.

2. Incluye el tiempo y el espacio quiere decir que es ubicua y atemporal. La luz de la conciencia ilumina el pasado, el presente y el futuro. Miramos hacia las galaxias más lejanas en el tiempo y en el espacio y podemos llegar a conocerlas gracias a la luz de la conciencia. Miramos el mundo subatómico y podemos llegar a conocerlo gracias a la luz de la conciencia. Mientras que tanto el conocimiento como el proceso cognitivo están condicionados por el tiempo-espacio, la conciencia no lo está. La conciencia no surge del tiempo-espacio sino que el tiempo-espacio surge de la conciencia. Esto es, si no hay conciencia del espacio-tiempo, sencillamente no hay espacio-tiempo.

3. Es vacua quiere decir que es inefable, imposible de aprehender mediante el conocimiento sensorial ni mediante el conocimiento categórico (racional). Dado que no se puede decir de ella que sea amarilla ni roja, ni salada ni dulce, ni áspera ni suave, ni perfumada ni maloliente, ni deseable ni odio- sa, ni melodiosa ni cacofónica, ni alta ni baja, ni buena ni mala, ni cercana ni lejana, ni medible ni no-medible, etc. Decimos que es vacío (sunya) o vacuidad (sunyata).

Aunque la conciencia sea incognoscible mediante los sentidos, la emoción y las categorías racionales, esto no quiere decir que no pueda ser experimentada en su verdadera naturaleza. Precisamente, la experiencia de la verdadera naturaleza de la conciencia (que, no olvidemos, es la fuente de todo conocimiento) es la meta principal de la tradición budista, la experiencia que, como ya sabemos, es llamada iluminación. Un ejemplo claro del despliegue de la conciencia, es el instante de la concepción de una nueva vida humana. Este momento puede ser entendido como el instante en el que una cierta cantidad de energía alcanza su máximo nivel de densificación, de materialización, de conciencia. La energía acaba de convertirse en materia, la onda acaba de convertirse en corpúsculo. En el momento de la concepción, una cierta cantidad de energía cósmica difusa se concentra en un corpúsculo muy pequeño, cuyo potencial es fuertísimo, con una densidad material enorme, tan enorme que a partir de él se van a desplegar todas las potencialidades de la vida humana (incluso la potencialidad de destruir el planeta).

A partir del nacimiento, la energía contenida en él va a experimentar un proceso evolutivo en el que cada nuevo nivel de organización alcanzado será superior (más complejo) al anterior. Estos niveles son modalidades de ser. En cada uno de esos niveles el ser se siente, se percibe a sí mismo de manera distinta. Estas distintas maneras de percibirse a sí mismo vienen dadas por los distintos niveles de organización que la energía va adoptando en su proceso evolutivo.

Para los físicos cuánticos, la energía en forma de ondas está continuamente transformándose en energía en forma de corpúsculos, y los corpúsculos están continuamente transformándose en ondas. Esta es la pulsación básica del mundo subatómico, es decir, la pulsación básica de nuestra realidad. Para el budismo zen, la vida está continuamente transformándose en muerte y la 
muerte en vida. La vacuidad se vuelve fenómeno, los fenómenos se vuelven vacuidad. en el budismo zen: desde el macrocosmos al microcosmos, la energía vital pulsa desde un máximo nivel de sutileza (máxima expansión de la energía) hasta un máximo nivel de densidad (máxima concentración de energía). Encontramos que este principio es válido en cada uno de los niveles de organización de la energía, desde las amebas, las partículas subatómicas, las galaxias, las estrellas, el cuerpo humano, las emociones humanas, la mente humana, hasta el pleno despertar de la conciencia.

En la tradición budista, en lugar de ser autosuficiente, la conciencia es más como la superficie de un mar: Dependiente de profundidades desconocidas ("condiciones", como las denomina el Buda) que no se pueden asir porque son una manifestación de las mismas. El problema surge porque esta conciencia condicionada, y por ello inestable, quiere fundamentarse para realizarse. Pero realizarse es objetivizarse -que significa aferrarse a sí mismo, puesto que un objeto es lo-que-esaferrado. El yo egótico está en continua tentativa de objetivizarse a sí mismo, aferrándose a sí mismo, algo igual de imposible que la tentativa de que una mano se agarre a sí misma.

Para el budismo zen, el tomar conciencia de que somos Luz y el vivir de acuerdo a ello es la meta última de la vida humana. El objetivo de la práctica espiritual consiste así en desarrollar esta conciencia, en despertarse a ello. Buda enseñó que la existencia humana es sufrimiento cuando se vive en la ignorancia ${ }^{19}$. ¿Qué es la ignorancia en el budismo? Etimológicamente, el término sánscrito avidya significa "poco claro", "oscuro". Hace referencia al velo que empaña la conciencia humana y le impide tener un conocimiento claro y luminoso de la realidad. Ignorancia puede ser entendido pues como conocimiento deficiente, por impreciso y limitado, del yo (sujeto, principio de identidad) y de la realidad. Ignorancia significaría en este contexto la negación de la pulsación energética vida-muerte-renacimiento, o energía-materia o carga-descarga. Al apegar- nos a un estado momentáneo de la energía, los seres humanos tratamos de paralizar el proceso energético que por su propia naturaleza es dinámico y pulsátil. De aquí que la enseñanza de Buda tiene como fin el ayudarnos a disolver el apego a la existencia de seres individuales (corpúsculo) y despertarnos a la realidad: el ser humano es un proceso energético o energía dinámica (onda). Según lo anterior, somos ondas de energía que eventualmente adoptan la forma de cuerpo, emoción, mente y conciencia. Algunos pensadores opinan que entre lo corporal-energético y lo espiritual no hay contradicción, sino una profunda complementariedad, hablando del legado oriental. La tarea en la rueda del samsara es ocuparse de desbloquear la pulsación de la energía vital en unos niveles del ser y las vías espirituales hacen lo mismo en otros niveles.

Todos los niveles del ser (corporal, emocional, mental y espiritual) son la manifestación de la misma energía cósmica, la cual se organiza en cada uno de estos niveles siguiendo una dinámica pulsátil concentración-expansión, simplicidad-complejidad, condensación-disolución, carga-descarga. En el momento de la muerte, según el pensamiento budista, toda la energía concentrada-condensada en el individuo (corpúsculo) se expande-disuelve en el río de la energía cósmica (onda) que antecedió al nacimiento del individuo y sucederá a su muerte. A su vez, esta energía en forma de onda volverá a materializarse en un corpúsculo concreto en el momento de la concepción. Esta es la Rueda de la vida y de la muerte, este es el flujo universal de la energía.

Según la opinión de muchos pensadores orientales, las culturas occidentales están atrapadas en el nivel mental, esto quiere decir que vivimos confundidos por los conceptos y las imágenes mentales que genera nuestra psiquis, que reaccionamos más a las imágenes mentales que a las cosas en sí. Por ejemplo, reaccionamos más ante el término árbol, con la palabra árbol, con la imagen mental que tenemos de un árbol, que con el árbol en sí. Esto impide que cada persona tenga acceso al estado de iluminación en el "aquí y ahora" o satori.

19 Dalai Lama. El arte de vivir en el nuevo milenio. Barcelona: Grijalbo, 2000, p.34. 
Dentro de esta reflexión sobre el budismo zen podríamos preguntarnos qué es el ego en la tradición del lejano oriente. El ego es la imagen que cada uno tiene de sí mismo, pero que la mayor parte de las veces no tiene nada que ver con lo que el ser es realmente. La imagen que cada uno tiene de sí mismo ha sido condicionada por la educación, por el sistema social y cultural. Según esto, cuando cualquier ser humano occidental se mira a sí mismo, resulta que la imagen que tiene de sí mismo no tiene en cuenta su funcionamiento corporal, muchas veces ni siquiera su vida sexual, no está incluida su capacidad emocional y no están incluidas sus necesidades y tendencias espirituales, más aún, no se desarrolla la propia energía o " $C h r$ '. Si el ego está constituido mentalmente mediante esta forma de pensamiento dualista, el ego debería ser capaz de morir sin una muerte física. Eso es precisamente lo que afirma el budismo: el sentido del yo puede desaparecer, pero permanece otra cosa que no puede morir, puesto que nunca nació. Anatma es la "vía del medio" entre los extremos de lo eterno (el yo sobrevive a la muerte) y la aniquilación (el yo es destruido con la muerte). El budismo resuelve el problema de la vida-y-la-muerte, proponiendo sencillamente la eternidad de la energía (Valerie Hunt. Mente infinita. Barcelona: Plaza y Janés, 2001). La evaporación de esta forma de pensamiento dualista revela lo que es anterior a ello, que tiene muchos nombres, el más común es "lo no-nacido». Que equivaldría a lo que "siempre ha existido", es decir la Luz, en las grandes tradiciones espirituales, incluyendo el budismo (José Francisco González. Conocer la mente. Madrid: Promolibro, 2003).

\section{La práctica del zen y la ruptura con el mundo de las ilusiones}

\author{
No hay ni nacimiento ni muerte, \\ ni crecimiento ni disminución.
}

\author{
El mundo infinito es parecido a una corriente \\ que permanece siempre pero en movimiento. \\ No podemos ver la totalidad de la corriente, \\ sólo algunas partes son visibles. \\ Pero esa parte que vemos no es más que ilusión.
}

Sutra de la Gran Sabiduría

El zen, como filosofía práctica en el budismo, es una vía para romper la imagen mental ilusoria que el ser humano tiene de sí mismo y por ende de la realidad. En la tradición Budista, la ilusión recibe el nombre de "maya": El mundo físico no es real, sino que equivale a una ilusión o a veces se le equipara con un sueño, por ende, es inconsistente, "anitya", efímero, pasajero (Sigfried Brandon. Diccionario de religiones comparadas, Madrid: Cristiandad, 1975). Mediante la práctica del zen, la persona pretende una liberación del mundo ilusorio que contiene necesariamente dolor, depresión, tristeza y angustia. Como sujetos conocedores "definimos" nuestra identidad con base en nuestras sensaciones, percepciones, categorías conceptuales, emociones, etc, es decir, como seres sujetos al tiempo y al espacio. Desde esa imagen, el ser humano, trata de conocer la realidad y para ello utiliza procesos cognitivos íntimamente condicionados por su identidad, es decir, por el tiempo y por el espacio, por la materia, por el cerebro. El budismo llama a este tipo de conocimiento "relativo" o "ilusorio". En la práctica de la meditación zen se trata de ir más allá del mundo ilusorio. En ella la postura corporal es absolutamente importante, se asume la posición de la "flor de loto"20. Para los occidentales esta postura nos resulta muy difícil, porque no se tiene conciencia corporal, porque no se conoce el propio cuerpo y no se está en contacto con él. Lo primero que una persona se encuentra cuando se sienta a hacer zen es que la mente está disparada. La práctica de la meditación en zen es el punto clave para romper esa imagen ilusoria que se crea cada cual de sí mismo, lo que se denomina "ego".

20 Cuando el Buda, en la iconografía oriental, se representa como vencedor del mundo ilusorio, omnisciente, se suele representar en posición de flor de loto, mediante una imagen dorada, lleno de luz, con las piernas cruzadas y en acción meditativa. Dicha imagen es conocida también como Tathágata. 
Por una parte, el zen, ayuda a tomar conciencia de la naturaleza emocional y corporal de cada persona y, por otra, permite trascender el funcionamiento conceptual, la mente cognitiva, para acceder a un reino de ser y de existencia que podemos llamar "espiritual" o "energétiCO", con sus normas específicas y sus reglas cognitivas propias, distintas de la mente racional y conceptual. La meditación zen ayuda a tomar conciencia de los niveles evolutivamente anteriores que hemos reprimido u olvidado, como son el corporal y el emocional. Debido a esto, la práctica de la meditación puede hacer ver que se capten lesiones importantes en el desarrollo psicofísico, en la conciencia corporal y emocional. Cuando se ha producido la integración personal necesaria entre el cuerpo, la emoción y la mente, y se ha establecido un equilibrio justo y armónico real entre esa tríada, según el maestro Tohei (Meditación zen, Roma: Del Vecchio, 1987), la práctica del zen permite acceder a los reinos superiores del ser (superiores en cuanto de mayor nivel de complejidad, mayor nivel de sutileza y mayor nivel de acercamiento a nuestra auténtica naturaleza).

\section{Conclusiones}

Esta dinámica propuesta por el budismo zen nos permite desarrollar una visión global donde entran todas las facetas de lo humano: la capacidad de sentir la vida, de sentir el océano energético, a lo que identificamos con el término de "espiritual". En Oriente, entender el flujo energético del universo, nos permite la integración de funciones específicas del animal humano y las funciones vitales y energéticas en general. Cuando la pulsación energética, los procesos instintivos, se ven limitados, se ven manipulados, se ven condicionados desde la vida intrauterina por dinámicas familiares, sociales, culturales, que están lejos de lo que es el principio o los principios de la vida, se crea una estructuración energética alterada que tiende a separarse lo menos posible de su funcionalidad, pero que necesariamente, para adaptarse, tiene que compensarse, y esto significa siempre una cierta desestabilización o distorsión de lo que denominados "realidad". La meditación zen propone una nueva comprensión de la realidad del ser humano en términos de energía-pulsación-onda, términos afines con la teoría cuántica (Katsuhiko Yazaki El camino a Liang Zhi. Barcelona: Limpergraf, 2001).

En el pensamiento del budismo zen hay cuatro posibilidades para trabajar la dinámica energética en conexión con la mente y el cuerpo en el ser humano. A continuación, brevemente se describen:

a) El silencio como la posibilidad de encontrarnos con nuestro propio momento, con nuestro aquí y ahora; el silencio supone encontrarse con el sufrimiento que lleva cada ser humano dentro de cada uno: entender la dinámica del sufrimiento como una ilusión que se puede deshacer, facilita el andar a lo largo del camino en búsqueda de nuevas alternativas energéticas de curación. El silencio supondría por tanto, facilitar lo que normalmente no hacemos, que es el mantener contacto con el propio ser interior. La meditación es un medio para lograr el silencio.

b El contacto con la naturaleza en su globalidad, Los principios orientales insisten copiosamente en este aspecto-, potenciar la aproximación a aquello de lo que somos parte; poder llegar a sentir que somos parte de esa única realidad. En la filosofía zen es primordial el arte de convivir con los elementales de la naturaleza: agua, aire, tierra, madera. Lejos de una noción romántica, el zen propone una "integración natural" con el cosmos, al respecto existe una amplia bibliografía que se ha ido introduciendo con éxito en Occidente.

c) Tomar conciencia de lo cotidiano, del día a día, y de lo que cada uno hace, es una forma de enseñanza continua, allí se descubren las verdades de la vida. Si sabemos mirar sintiendo lo "vivo", podemos acercarnos a la vida, entrando en contacto con ella y entendiéndola desde otra dinámica.

d) El contacto con "lo otro", o con el cosmos que permite la posibilidad de abandonarse, de sentir el 
amor vinculado a lo humano y lo cósmico: la capacidad de entrega y de amor a una persona, a una comunidad; de vivir también un mayor contacto con la vida a través de la experiencia de fusión, de perderse en el otro, o en el "absoluto", del placer a partir de la elección y la entrega, de la unión con la trascendencia o la defensa pacífica de nobles ideales: paz, solidaridad, compromiso.

e) Ir más allá de la ilusión. En el escenario del mundo zen, cada cual es el protagonista, tejiendo su propia historia, la tarea es "deshacer" el reino de ilusiones fabricadas por el ego, superar una serie de obstáculos buscando esa solución. Uno de estos obstáculos, es como un espejo que está situado en medio del desierto. Esta metáfora significa que el ser humano debe atravesar la realidad aparente, abandonar el ego que cree ser o la identidad escindida del resto del cosmos que cree ser. Para eso tenemos que pasar a través del espejo y ese espejo lo primero que hace es reflejar la realidad, nuestra realidad básica, nuestra realidad corporal, emocional y psicológica. En la puerta de entrada al reino espiritual se encuentra un espejo como este. Para acceder más allá, es precisa una profunda recapitulación corporal, emocional y psicológica. El destino del hombre es atravesar ese espejo, llamado ilusión en el budismo.

Según el maestro zen Menzan Zuiho(siglo XVIII): "Dado que las personas están cegadas por la mente ilusoria, no pueden ver con claridad el cuerpo completo de la realidad y, como consecuencia de esto, perciben cosas en términos de bueno o malo, ser o no-ser, vida o muerte, seres ordinarios y Budas. Si nuestros ojos estuvieran abiertos nos daríamos cuenta inevitablemente que el conocimiento o la perspectiva adquiridos a través de nuestras propias experiencias personales no son la realidad completa. Esta es la razón por la que nadie pue- de liberarse de los engaños si no disuelve antes la ignorancia".

Lo anterior sólo podremos hacerlo, según el budismo zen, cuando coloquemos cada uno de los niveles de nuestro ser en orden, es decir, cuando recuperemos conscientemente nuestro cuerpo, nuestra capacidad emocional y la condición de nuestra mente. Entonces, podemos atravesar el espejo y penetrar en los reinos espirituales. De lo contrario, los filtros de la personalidad van a distorsionar también nuestra experiencia espiritual. Esta metáfora cabe dentro de la tradición budista, cuando el hombre va más allá de la ilusión de los sentidos, más allá de sí para llegar a la "gran ilusión" del sufrimiento humano y llegar incluso a superarla y así contemplar la luz de su propia realidad.

Aún quedan muchos elementos valiosos por explorar del universo zen en conexión con la problemática ciencia-espiritualidad, desde el presente trabajo se vislumbran estos temas: la conciencia y la objetivación de la realidad, la percepción de los fenómenos y la experiencia del vacío, la conexión energía-materia, el problema del espacio-tiempo infinito y la percepción del yo temporal.

Para concluir, en un relato, Katsuhiko Yazaki cuenta que después de una semana de meditar en el Monasterio Zen de Kido Inoue se quedó atónito al descubrir por primera vez lo que él denominada "yo". Escribió: "Los seres humanos, al separar el mundo del ser, la naturaleza de la humanidad y su ser de los demás, quedan atrapados en las ilusiones para proteger su ego. Nos olvidamos que este universo, como diría Vivekananda, no es más que un gimnasio donde se ejercita el alma"21.

En trabajos posteriores, se profundizarán dichas temáticas en conexión con otras importantes tradiciones del lejano oriente: el hinduismo y el taoísmo. 


\section{Bibliografía}

Villalba, Dokushô, Meditación zen. Fundación Comunidad Budista Soto Zen, Templo Luz Serena, Madrid, 2005.

Villalba, Dokusho. ¿Qué es el Zen?, Kairós, 1998, p. 89.

Dalai Lama. El arte de vivir en el nuevo milenio. BarceIona: Grijalbo, 2000.

Mandukya Nikilanahda. El Budismo. New York: Centro Vivekananda, 1990.

Autores Varios. El budismo zen, ayer y hoy, Barcelona: Terra, 1998.

Yogananda, Paramahansa, Estudios sobre la mente, Buenos Aires: Troquel, 1998.
Albright, William (traducción de Manuel Dávalos). Las grandes religiones del mundo, Nueva York: Golden Press, 1967.

Radhakrisna. La naturaleza del hombre, Buenos Aires: Troquel, 1986.

Autores Varios. El hombre en busca de Dios, Nueva York: Watch Tower, 1990.

Deshimaru, Roshi, Taizen. El zen, Roma: Del Veqquio, 1998.

Autores Varios. Diccionario de las religiones comparadas, Barcelona: Verbo Divino, 1998.

Doods, Albert (1975). The feseability of psychical theory of ESP. En: Journal of the Society for Psychical Research, No. 57, p. 238. 